\title{
Metachronous Granular Cell Tumor of the Descending Colon
}

\author{
Binav Shrestha ${ }^{a}$, Mazin Khalid ${ }^{\mathrm{a}, \mathrm{d}}$, Vijay Gayam ${ }^{\mathrm{a}}$, Osama Mukhtar ${ }^{\mathrm{a}}$, Shivani Thapa ${ }^{\mathrm{a}}$, \\ Amrendra K. Mandal ${ }^{\mathrm{a}}$, Jaspreet Kaler ${ }^{\mathrm{a}}$, Mowyad Khalid ${ }^{\mathrm{b}}$, Pavani Garlapatia, \\ Shamah Iqbal ${ }^{\mathrm{c}}$, Gerald Posner ${ }^{\mathrm{a}}$
}

\begin{abstract}
Granular cell tumors (GCTs) are uncommon tumors. They are believed to be neuronal in origin and are usually found in the head and/ or neck area of the body. They have also been reported in various locations of the gastrointestinal (GI) system, usually discovered during routine screening colonoscopy. We report a case of GCT in a 58-yearold asymptomatic African American female as a metachronous tumor of a well-differentiated adenocarcinoma of the sigmoid colon, which was an incidental finding in screening colonoscopy. To our knowledge, this is the first case with GCT identified as a metachronous tumor following an adenocarcinoma of the colon.
\end{abstract}

Keywords: Granular cell tumor; Metachronous tumor; Colorectal cancer; Colonoscopy; Surveillance

\section{Introduction}

Granular cell tumors (GCTs), also known as Abrikossoff's tumors, are among the most uncommon tumors which can progress into malignancy [1]. These mesenchymal tumors are composed of polygonal cells containing eosinophilic granules resembling Schwann cells under an electron microscope and stain positive for S100 protein, thus believed to be of neural cell origin. They are most commonly found in the head and/ or neck areas, of which $70 \%$ are located intraorally [2]. A few of the other more rare sites reported are the extremities, axillae, rectum and sigmoid colon [3-5]. These tumors are usually less than $3 \mathrm{~cm}$ in size. Only $2 \%$ of all GCTs are malignant $[6,7]$. We report a case of an asymptomatic descending colon granular cell metachronous tumor discovered during a follow-

, accepted May 11, 2018

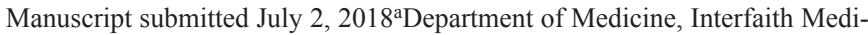
cal Center, Brooklyn, NY, USA

bepartment of Medicine, Detroit Medical Center, Wayne State University, MI, USA

${ }^{\mathrm{c}}$ Department of Pathology, Interfaith Medical Center, Brooklyn, NY, USA

${ }^{\mathrm{d} C}$ Corresponding Author: Mazin Khalid, Department of Medicine, Interfaith

Medical Center, Brooklyn, NY 11213, USA.

Email: dr.mazinkhalid@gmail.com

doi: https://doi.org/10.14740/gr1045w up colonoscopy after 13 months of a resection of a well-differentiated sigmoid adenocarcinoma by polypectomy.

\section{Case Report}

Our patient is a 58-years-old African American female with past medical history of chronic hepatitis C infection (HCV), hypothyroidism, uterine fibroids with iron deficiency anemia and hypertension. She was brought into the psychiatry emergency room for having suicidal ideation. She denied smoking and alcohol intake. She had no history of abdominal pain or inflammatory bowel disease; no family history of colon cancer or other malignancies. Her vital signs were stable and she had an unremarkable physical exam. Her laboratory workup and imaging were within normal limits. Thirteen months prior to the admission, the patient underwent routine screening colonoscopy which revealed well-differentiated sigmoid adenocarcinoma; the margins of resected polyp were negative for malignancy. Gastroenterology consult was ordered for follow-up and they recommended follow-up with a complete colonoscopy. The repeat colonoscopy during this visit showed a $2-4$ $\mathrm{mm}$ nodule in the descending colon that was not noted in the previous colonoscopy (Fig. 1).

CEA levels were normal with a value of $3.3 \mathrm{ng} / \mathrm{mL}$ (reference $<3.9 \mathrm{ng} / \mathrm{mL}$ ). The histopathology analysis showed intra-

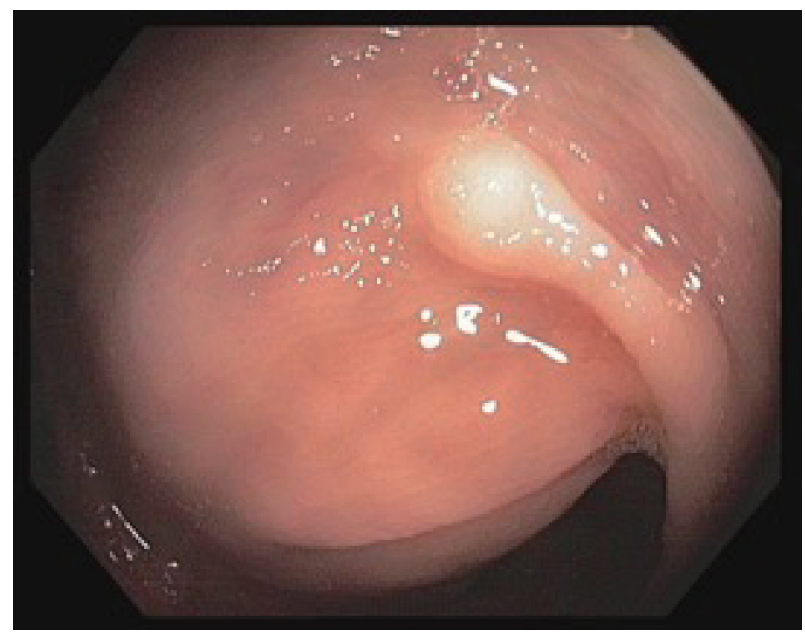

Figure 1. Colonoscopy image showing granular cell tumor in the descending colon seen as a nodule 2 - $4 \mathrm{~mm}$ in greatest dimension. 


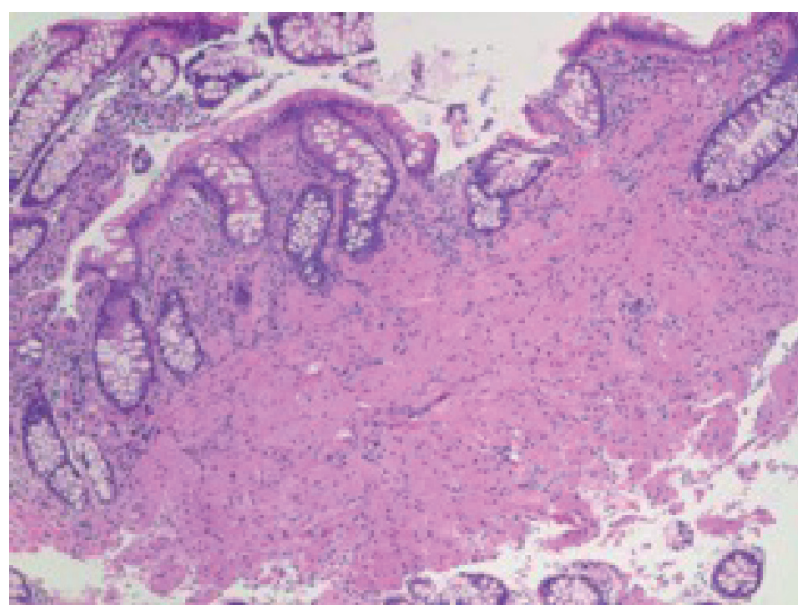

Figure 2. H\&E stain of the specimen showing large cells with prominent granular cytoplasm and small nucleus in the mucosa.

mucosal GCT. The diagnostic features of GCT were all met in our case which include: granular eosinophilic cytoplasm (Fig. $2,3)$, small uniform nuclei with absent mitotic activity, S-100 protein (Fig. 4), CD68, and CD56 (Fig. 5, 6) positivity [2].

In addition, our case was positive for SOX10 using an EP268 antibody (Fig. 7). There was no evidence of metastasis or lymph node involvement. As the gastroenterologist wanted to ensure the absence of other lesions, a colonoscopy was repeated 15 days later and no additional lesions were identified. The patient was transferred to another psychiatric facility in a stable condition and planned to follow-up colonoscopy in 1 year.

\section{Discussion}

GCT presence in the gastrointestinal tract is unusual. If found, then it is usually located in the submucosal areas, but rare reports of subserosal and muscle layer involvement have been reported [8]. GCTs are usually found incidentally during screen-

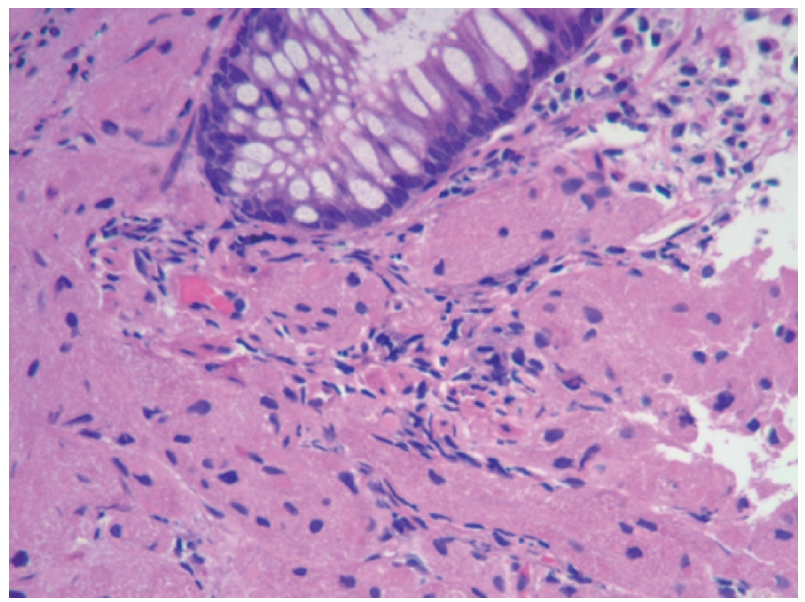

Figure 3. H\&E stain of the specimen showing mucosa infiltrated by large cells with granular cytoplasm. No mitosis was identified.

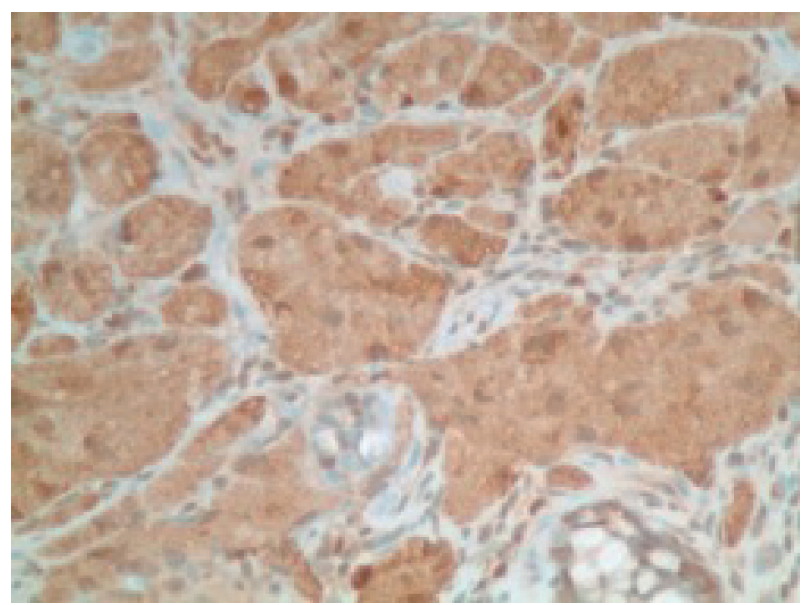

Figure 4. Immunohistochemical stain positive for S100 protein in tumor cells.

ing colonoscopy but, to our knowledge, this is the first time been reported as a metachronous tumor of the descending colon. The endoscopic features of GCT might resemble polyps; hence, the final diagnosis is made based on the histopathological results. We performed endoscopic snare polypectomy during screening colonoscopy as it was intramucosal in location.

GCTs are usually benign but rarely they can present as malignant lesions $[6,7]$. Since it is a potentially malignant tumor, Fanburg-Smith histopathological criteria are used to confirm its malignant nature [6]. These criteria use six histological features: necrosis, spindling, vesicular nuclei with large nucleoli, mitotic activity (at $400 \times$ magnification $>2$ mitoses $/ 10$ high power field). Upon examination, none of these criteria were met in our case. There have been cases of the tumors which presented with benign histology but later presented as lung metastasis as described by Thacker MM et al [9]. Thus, differentiating benign from malignant variant is important and is equally challenging. The malignant variant carries a mortality rate of $40 \%$ and has a high propensity to metastasis and recurrence [10].

Colorectal cancers (CRC) diagnosed 6 months after the

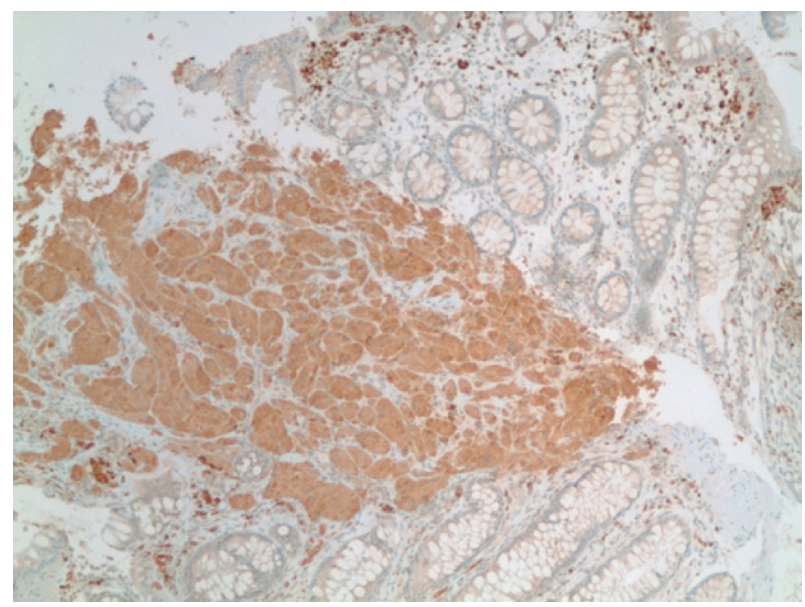

Figure 5. Immunohistochemical stain positive for CD68 in tumor cells. 


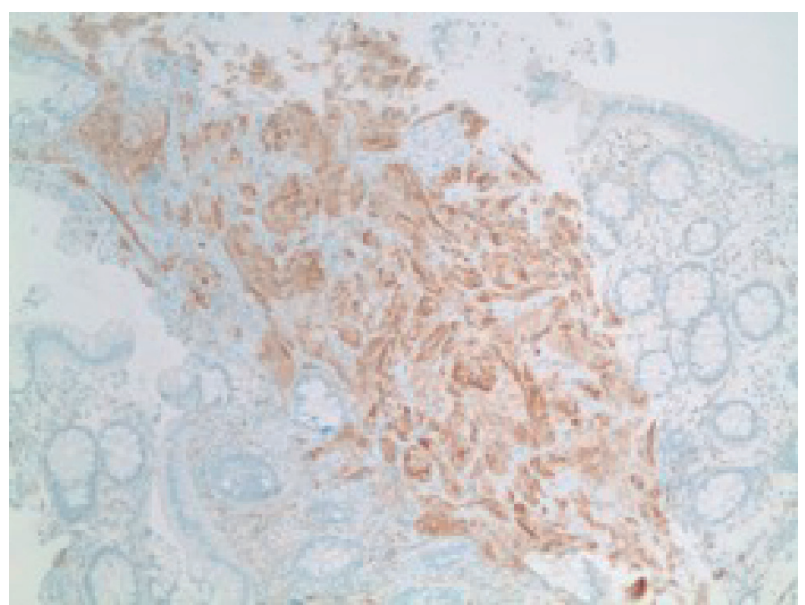

Figure 6. Immunohistochemical stain showing positive for CD56 in tumor cells.

primary CRC surgery is termed metachronous CRC $[11,12]$. The incidence of colonic and rectal metachronous tumors are reported to be $0.3-0.35 \%$ per year which could potentially present even decades after the index CRC [13]. In one study, Park IJ et al reported $39(0.7 \%)$ of metachronous tumors $(\mathrm{N}=$ $5,447)$ with an average age of 53 years. Our patient was older (58 years) as compared to this study and the average age of sporadic colorectal cancer patients. Studies included in recommendations of the US Multi-Society Task Force on Colorectal Cancer (MSTF) reflected an incidence of 1.6\% metachronous cancers in 15,803 patients among which $30 \%$ were detected within 2 years very similar to our report [13]. On the other hand, the proximal colon was reported to be at greater risk for metachronous tumors; unlike our case which presented in the distal colon [14]. Park et al also reported metachronous cancers to be more likely to occur in the right colon $(\mathrm{P}<0.003)$ and diagnosed earlier [11]. Netherlands Cancer Registry revealed $1.8 \%$ metachronous cancers are diagnosed between 7 months to 30 years after the initial CRC diagnosis, among which $40.8 \%$ were diagnosed within 3 years of initial CRC and these were attributed to the missed lesions in $43 \%$, nonadherence to surveillance recommendations and incomplete resection in 5.4\%; de novo cancers accounted for only 5.4\% [13]. Five out of nine (around 55\%) metachronous cancers were diagnosed within 3 years in a randomized control trial (RCT) conducted by Wang et al [15] highlighting the importance of repeat surveillance with colonoscopy within 1 year. The occurrence of metachronous tumors due to a missed lesion is still a topic of debate. Index CRC of adenocarcinoma later presenting as GCT, like in our case, emphasizing the use of repeat surveillance colonoscopy and the significance of histologic examination of all polyps removed.

\section{Conclusions}

We report a case of GCT in descending colon as a metachronous tumor of a well-differentiated adenocarcinoma of sigmoid colon which was an incidental finding in screening colonos-

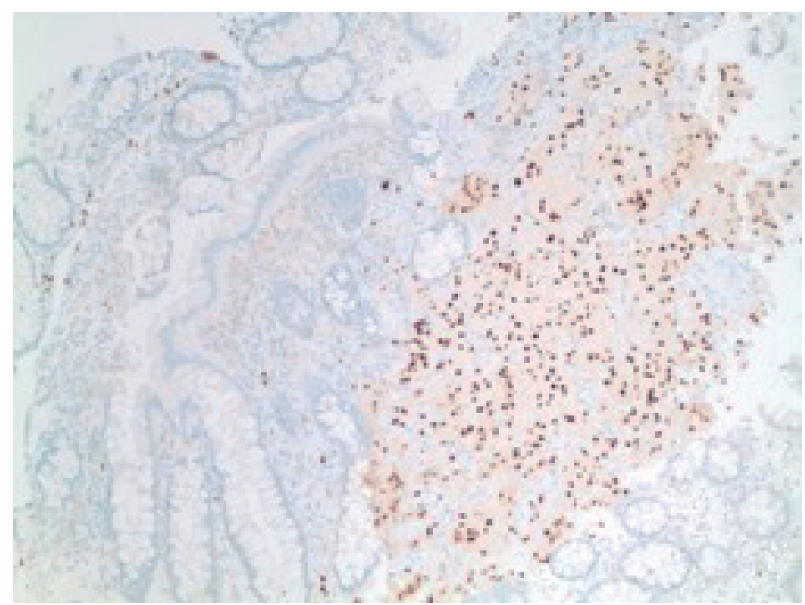

Figure 7. Immunohistochemical stain showing positive stain for SOX10 in tumor cells.

copy. These results highlight the importance of a follow-up colonoscopy within 1 year of resection of tumor at any stage. To our knowledge, this is the first case of GCT as a metachronous tumor.

\section{Conflict of Interest}

Authors have no conflict of interest.

\section{References}

1. Abrikossoff A, Uber myome. Virchows Archiv fur pathologische Anatomie und Physiologie und fur klinische. Medizin. 1926;260(1):215-233.

2. Kahn MA. Salivary gland tumours. Basic oral and maxillofacial pathology, vol 1. 2001:29-30.

3. Elkousy H, Harrelson J, Dodd L, Martinez S, Scully S. Granular cell tumors of the extremities. Clin Orthop Relat Res. 2000;380:191-198.

4. Endo S, Hirasaki S, Doi T, Endo H, Nishina T, Moriwaki $\mathrm{T}$, Nakauchi $\mathrm{M}$, et al. Granular cell tumor occurring in the sigmoid colon treated by endoscopic mucosal resection using a transparent cap (EMR-C). J Gastroenterol. 2003;38(4):385-389.

5. Nakachi A, Miyazato H, Oshiro T, Shimoji H, Shiraishi M, Muto Y. Granular cell tumor of the rectum: a case report and review of the literature. J Gastroenterol. 2000;35(8):631-634.

6. Fanburg-Smith JC, Meis-Kindblom JM, Fante R, Kindblom LG. Malignant granular cell tumor of soft tissue: diagnostic criteria and clinicopathologic correlation. Am J Surg Pathol. 1998;22(7):779-794.

7. Singh VA, Gunasagaran J, Pailoor J. Granular cell tumour: malignant or benign? Singapore Med J. 2015;56(9):513517.

8. Tsuchida T, Okada K, Itoi E, Sato T, Sato K. Intramuscular malignant granular cell tumor. Skeletal Radiol. 
1997;26(2):116-121.

9. Thacker MM, Humble SD, Mounasamy V, Temple HT, Scully SP. Case report. Granular cell tumors of extremities: comparison of benign and malignant variants. Clin Orthop Relat Res. 2007;455:267-273.

10. Rekhi B, Jambhekar NA. Morphologic spectrum, immunohistochemical analysis, and clinical features of a series of granular cell tumors of soft tissues: a study from a tertiary referral cancer center. Ann Diagn Pathol. 2010;14(3):162-167.

11. Park IJ, Yu CS, Kim HC, Jung YH, Han KR, Kim JC. Metachronous colorectal cancer. Colorectal Dis. 2006;8(4):323-327.

12. Rao D, Jayaraman S. Metachronous colorectal malignancies. Indian J Surg. 2011;73(5):368-369.

13. Kahi CJ, Boland CR, Dominitz JA, Giardiello FM, Johnson DA, Kaltenbach T, Lieberman D, et al. Colonoscopy Surveillance After Colorectal Cancer Resection: Recommendations of the US Multi-Society Task Force on Colorectal Cancer. Gastroenterology. 2016;150(3):758-768 e711.
14. Liu L, Lemmens VE, De Hingh IH, de Vries E, Roukema JA, van Leerdam ME, Coebergh JW, et al. Second primary cancers in subsites of colon and rectum in patients with previous colorectal cancer. Dis Colon Rectum. 2013;56(2):158-168.

15. Wang T, Cui Y, Huang WS, Deng YH, Gong W, Li CJ, Wang JP. The role of postoperative colonoscopic surveillance after radical surgery for colorectal cancer: a prospective, randomized clinical study. Gastrointest Endosc. 2009;69(3 Pt 2):609-615.

16. Hassan C, Gaglia P, Zullo A, Scaccianoce G, Piglionica D, Rossini FP, Morini S. Endoscopic follow-up after colorectal cancer resection: an Italian multicentre study. Dig Liver Dis. 2006;38(1):45-50.

17. Barrier A, Houry S, Huguier M. The appropriate use of colonoscopy in the curative management of colorectal cancer. Int J Colorectal Dis. 1998;13(2):93-98.

18. Rulyak SJ, Lieberman DA, Wagner EH, Mandelson MT. Outcome of follow-up colon examination among a population-based cohort of colorectal cancer patients. Clin Gastroenterol Hepatol. 2007;5(4):470-476; quiz 407. 